\title{
Mechanical Joining of Steel Sheets in Automotive Industry
}

\author{
Emil Spišák, Luboš Kašcák*
}

Institute of Technology and Management, Faculty of Mechanical Engineering, Technical University of Košice, Mäsiarska 74, 04001 Košice, Slovakia

Emil Spišák, prof. Ing. CSc., (born in 1955) is a professor at the Institute of Technologies and Management, Faculty of Mechanical Engineering, Technical University of Košice. He graduated from the Faculty of Mechanical engineering in 1980. He is the Head of the Department of Mechanical Engineering Technologies and Materials and Vice-Rector for Development and Construction of the University. Professor Spišák is the national secretary and a member of International Deep-Drawing Research Group. He works in the area of evaluating of material properties, material failures, analysis and quantification of production factors' influence in production of thin steel sheet stamping parts, modelling and simulation of technological processes, mainly forming processes. He is the author of 5 monographs and more than 350 publications in journals and conference proceedings in Slovakia and abroad. His published works were cited more than 100 times. He has been involved in 60 grant projects, research tasks and 50 projects implemented in industries.

Luboš Kaščák, doc. Ing. PhD., (born in 1974) is an associate professor at the Institute of Technologies and Management, Faculty of Mechanical Engineering, Technical University of Košice. He graduated from the Faculty of Mechanical engineering in 1999. He works in the area of evaluation of properties of joined steel sheets, focusing on resistance spot welding and mechanical joining. He is the author of 2 monographs and more than 100 publications in journals and conference proceedings in Slovakia and abroad. He has been involved in several grant projects and research tasks.

\begin{abstract}
Various ferrous and non-ferrous materials and their combinations are used in car body production in automotive industry. These materials need to fulfil several criteria before being approved. Some of the criteria are the results of regulation and legislation with the environmental and safety concerns and some are the requirements of the customers. In many occasions different factors are conflicting and therefore a successful design would only be possible through an optimized and balanced solution. The most commonly used method for joining the materials is resistance spot welding. Some materials or their combinations are very difficult or even impossible to join by resistance spot welding. Therefore, the car producers are seeking for alternative joining methods such as cold metal transfer, TOPTIG or mechanical joining. The paper deals with evaluation of properties of the joints made by two methods of mechanical joining - clinching and clinch-riveting. The steel sheets of DX51D+Z, H220PD and DC06 were used for experiments. The tensile test for observing the carrying capacity, metallographicall analysis and microhardness test were used for the evaluation of joints properties.
\end{abstract}

Keywords: Clinching, carrying capacity, clinchriveting, metallography, microhardness. 


\section{Introduction}

The assembly process development is driven by the automotive industry, especially by companies manufacturing car body elements. These companies are involved in developing and implementing new solutions which are more environmentally friendly [1]. The lightweight design of automobiles is one of the primary methods to realize energy conservation and emission reduction, thus the utilization of light material and structure has become the preferential approach as well as using various combinations of materials, such as combination of conventional drawing grade steel sheets and highstrength steel sheets $[2,3]$. The future trend is towards "intelligent"light weight construction, which means that for each produced part, the most suitable material regarding: functionality, durability, production, and costs are used. However, the assembly of those different parts presents a major challenge for multi-material-design and imposes a large cost factor [4]. The most used method for joining the steel sheets is the resistance spot welding. But most of steel sheets are galvanized to improve life of car body. In resistance spot welding of galvanised steel sheets, the wear of welding electrode becomes large due to the lower electrical resistance and melting temperature of the coating layer. Therefore alternative joining techniques, such as mechanical joining have attracted increasing interest and applications $[5,6]$. The most used methods of mechanical joining in car body production are clinching, clinch-riveting and self-piercing riveting. Clinching joining technique involves localized cold deformation of sheets without using additional elements even does not require a predrilled hole. The clinching process is a combination of drawing and forming that locks together sheets metal layers. Depending on the application and the required final mechanical strength, different clinching technologies may be used, with round or rectangular points, using fixed or floating dies [7, 8]. Clinch-riveting is a joining process similar to the self-pierce riveting and clinching. It is a single-step joining process, where the lock consisting of joined sheet metals is created by the plastic deformation of a solid rivet. [9]. Since the clinching and clinchriveting are mechanical joining and not metallurgical ones, the strength characteristics of the mechanical joining processes are different from those of the welding processes [10].
The authors decided to present the results of research of joining by clinching and clinch-riveting which are utilized in car body production.

\section{Principle of Joining Processes}

Clinching $(\mathrm{CL})$ is a high speed fastening technique, which uses a special punch and die to form a mechanical interlock between the sheet metals. As the joint is made by local plastic deformation of the sheets, the materials should have sufficient ductility to avoid cracking. Clinching can be used on coated and painted materials, and is suitable for joining dissimilar materials. Clinching involves the joining of materials by local forming and does not require an extra fastener - Figure 1. A punch forms the two materials to be joined into a die. A button is formed on the underside and provides an interlock between the sheets $[1,7]$.

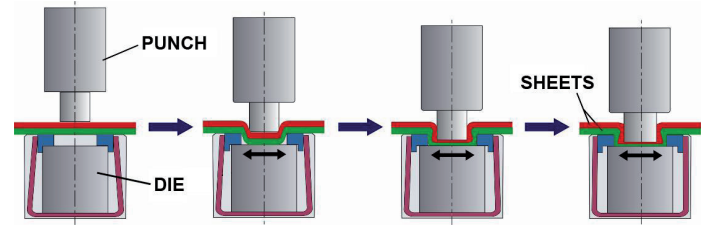

Fig. 1: Principle of clinching process [1].

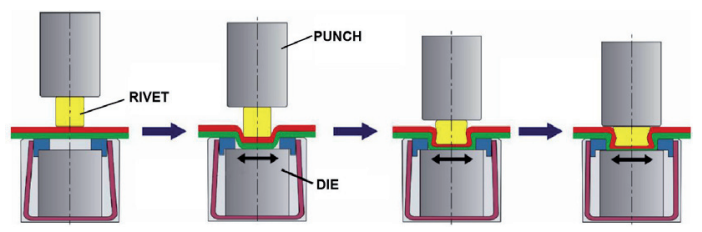

Fig. 2: Principle of clinch-riveting process [1].

Clinch-riveting (CR) is a cold process for joining two or more sheets by directly piercing the sheets with a rivet. CR process does not require a pre-drilled hole unlike the conventional riveting, the joining speed is the same level with that of the spot resistance welding, and the equipment is similar. The die on the underside of the materials causes the rivet to flare under the force, creating a mechanical interlock - Figure 2. The punch, under the pressure conveyed by a hydraulic power device, pushes the rivet to penetrate into the top plate, and the die shape causes the rivet to flare within the lower sheet in order to form a mechanical interlock [8]. Figure 3 presents the samples of utilizing of clinching and clinch-riveting methods 

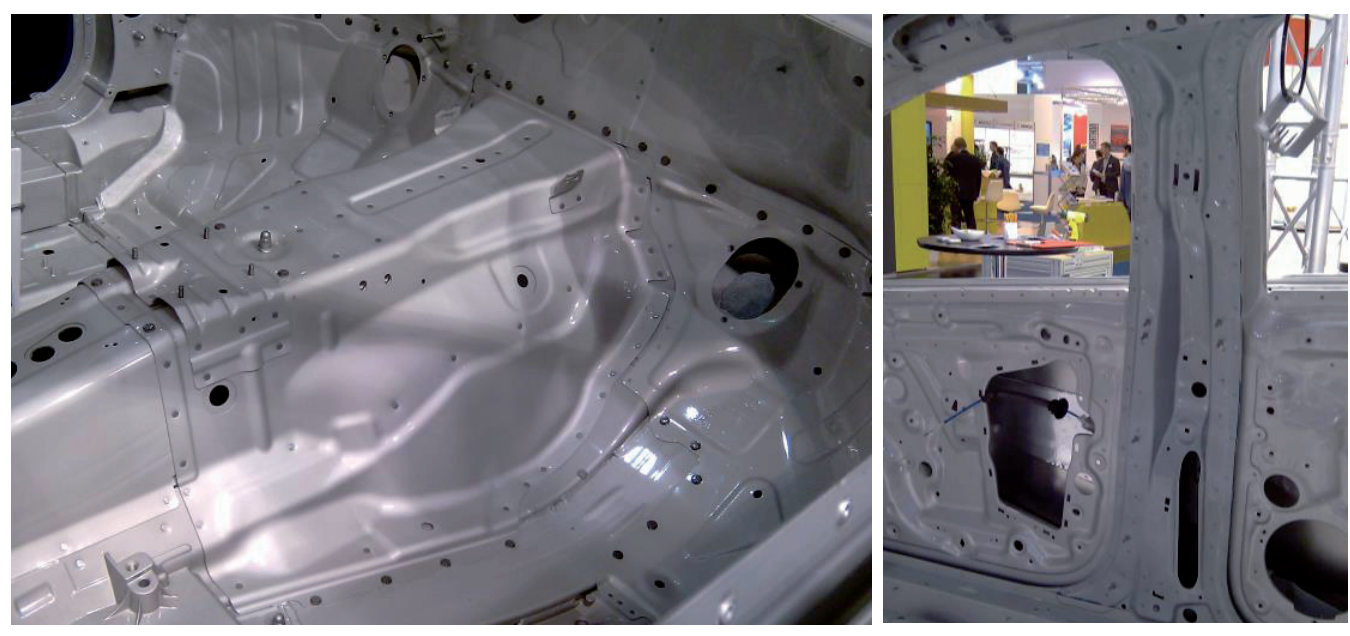

Fig. 3: Mechanical joining of sheets in body floor and B-pillar of AUDI A8 car body.

Table 1: Chemical composition of used steel sheets (in [\%] of wt).

\begin{tabular}{|l|l|l|l|l|l|l|l|l|}
\hline Material & $\mathbf{C}$ & Mn & Si & $\mathbf{P}$ & $\mathbf{S}$ & Al & Cu & Ni \\
\hline H220PD & 0.012 & 0.435 & 0.119 & 0.057 & 0.002 & 0.041 & 0.040 & 0.013 \\
\hline DC06 & 0.020 & 0.071 & 0.010 & 0.017 & 0.002 & 0.055 & 0.038 & 0.011 \\
\hline DX51D+Z & 0.064 & 0.178 & 0.007 & 0.016 & 0.002 & 0.120 & 0.041 & 0.002 \\
\hline Material & $\mathbf{C r}$ & $\mathbf{T i}$ & $\mathbf{V}$ & $\mathbf{N b}$ & $\mathbf{M o}$ & $\mathbf{C o}$ & & \\
\hline H220PD & 0.046 & 0.033 & 0.012 & 0.052 & 0.009 & 0.047 & & \\
\hline DC06 & 0.022 & 0.062 & 0.008 & 0.023 & 0.009 & 0.035 & & \\
\hline DX51D+Z & 0.023 & 0.002 & 0.005 & 0.015 & 0.004 & 0.019 & & \\
\hline
\end{tabular}

in car body parts of AUDI A8.

\section{Materials and Experiments}

The following hot-dip galvanized steel sheets were used for experiments: microalloyed steel HSLA H220PD with the thickness of $0.8 \mathrm{~mm}$, extra deep-drawing grade steel DC06 with the thickness of $0.7 \mathrm{~mm}$ and DX51D+Z with the thickness of 0.9 $\mathrm{mm}$. The chemical composition and basic mechanical properties of used steel sheets are shown in Table 1 and Table 2.

The following samples of the same material combinations were used for clinching and clinch-riveting:

- Samples A: H220PD and H220PD $\left(a_{0}=0.8 \mathrm{~mm}\right)$

- Samples B: DC06 and DC06 $\left(a_{0}=0.7 \mathrm{~mm}\right)$

- Samples C: DX51D and DX51D $\left(a_{0}=0.9 \mathrm{~mm}\right)$

In order to evaluate the properties of the joints, the following tests were performed: tensile test, microhardnesses test and a metallographical analysis. The samples with dimensions of $40 \times 90$
Table 2: Basic mechanical properties of used steel sheets.

\begin{tabular}{|l|l|l|l|}
\hline Material & Rpo.2 [MPa] & Rm [MPa] & A80 [\%] \\
\hline H220PD & 238 & 382 & 36 \\
\hline DC06 & 170 & $270-330$ & 41 \\
\hline DX51D+Z & $\geq 140$ & $270-500$ & 23 \\
\hline
\end{tabular}

$\mathrm{mm}$ and $30 \mathrm{~mm}$ lapping according to STN 051122 standard were used for the experiments (Figure 4). Seven samples were prepared for every combination of steel sheets, five samples for evaluation of carrying capacity, one sample for microscopy observation and one sample for microhardness test. Whereas the both used joining processes are cold joining processes, it was not necessary to clean the surfaces of the samples before clinching. The clinch-riveting method was carried out with the steel rivets of specified geometry (Figure 5). An average hardness of the steel rivet in five measurements was 357 HV0.1. The used rivets were made of material designed by catalog number A5 $\times 5-2 \mathrm{Al}$ 
by TOX Pressotechnik. The main alloy additives in their chemical composition, besides carbon, are $0.35 \%$ of $\mathrm{Al}$ and $1.5 \%$ of $\mathrm{Mn}$.

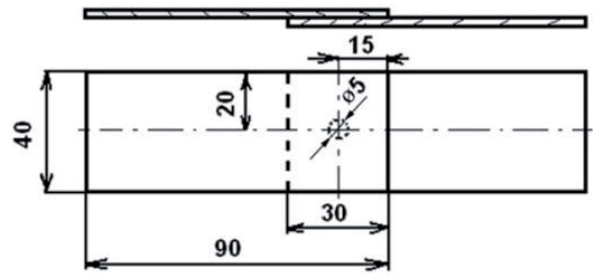

Fig. 4: Sample for tensile test.
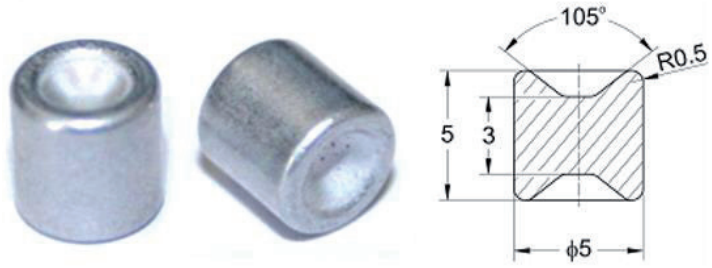

Fig. 5: Rivets used in CR joints.

The carrying capacities of the $C L$ and $C R$ joints, were evaluated according to standard STN 051122 - Tension test of spot welded joints. This test was used for measuring the maximum carrying capacities Fmax of the joints. The test was carried out on the metal strength testing machine TIRAtest 2300 produced by VEB TIW Rauenstein, with the loading speed of $8 \mathrm{~mm} / \mathrm{min}$. Microhardnesses analysis was realized according to STN EN ISO 6507-1 standard with the applied load of $980 \mathrm{mN}$ in the range of $10-15 s$.

\section{Results and Discussion}

The tensile tests were executed under displacement control conditions on the specimen configurations in order to characterise the static behaviour of the joints. The maximum shearing load was the most significant value obtained from the loaddisplacement curves as shown in Figure 6 - 8. The form of the curves indicates the behaviour of the joints under loading. The shearing load is higher for $C R$ joints than for $C L$ joints in all observed combinations of joined steel sheets.

All observed samples of $C R$ joints had higher values of carrying capacities in comparison to $\mathrm{CL}$ joints. On average, the $\mathrm{CL}$ joints reached 21\% (samples A), 22\% (samples B) and 30\% (samples C) of carrying capacities of $C R$ joints. The capacity for deformation in the case of $\mathrm{CL}$ joint is considerably smaller than the CR joint.

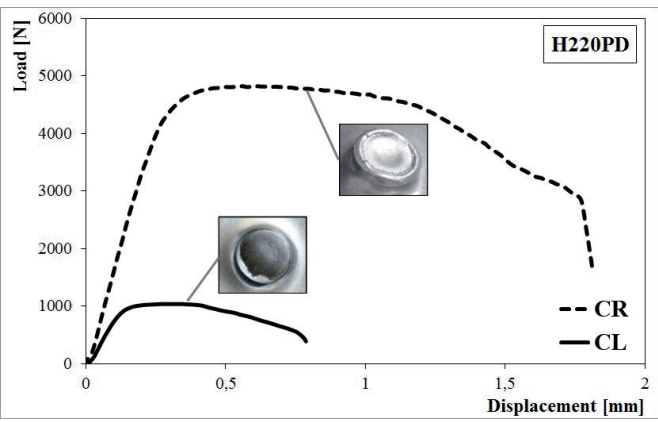

Fig. 6: Load-displacement curves of $C L$ and $C R$ joints of sample $A$ (H220PD).

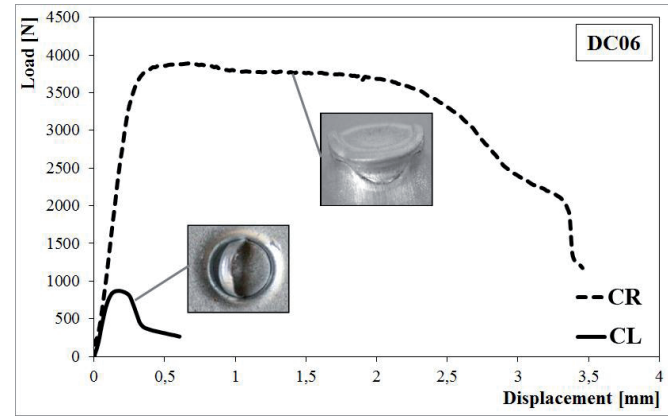

Fig. 7: Load-displacement curves of $C L$ and $C R$ joints of sample $B$ (DC06).

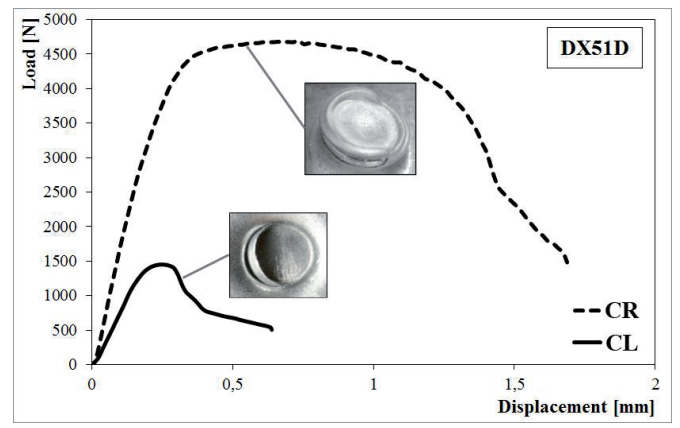

Fig. 8: Load-displacement curves of $C L$ and $C R$ joints of sample $C$ (DX51D).

The average value of maximum shearing load was: approx. $4800 \mathrm{~N}$ for sample A with the corresponding displacement about $0.4 \mathrm{~mm}$, approx. $3800 \mathrm{~N}$ for sample B with the corresponding displacement about $0.5 \mathrm{~mm}$ and approx. $4800 \mathrm{~N}$ for sample $C$ with the corresponding displacement about $0.4 \mathrm{~mm}$. During the joining process of clinch-riveting, the rivet and the riveted sheets 
undergo massive deformation in order to form the mechanical interlock. This energy is stored within the interlock, leading to higher energy absorption than that of $\mathrm{CL}$ joint. Joints made by clinch-riveting method (CR joints) failed in the manner of a pressstud in combination with a failure of one edge of the joint and joints made by clinching ( $\mathrm{CL}$ joints) failed at the neck of the joint (Figure 6 - 8). Both modes result in loosening of the joint after quite small displacements. In the press-stud mode, insufficient deformation produces minor interlocking of the sheets and will lead to failure. In the second mode, there is insufficient material in the neck of the joint and loading will result in failure in the neck; excessive elongation in the region of the
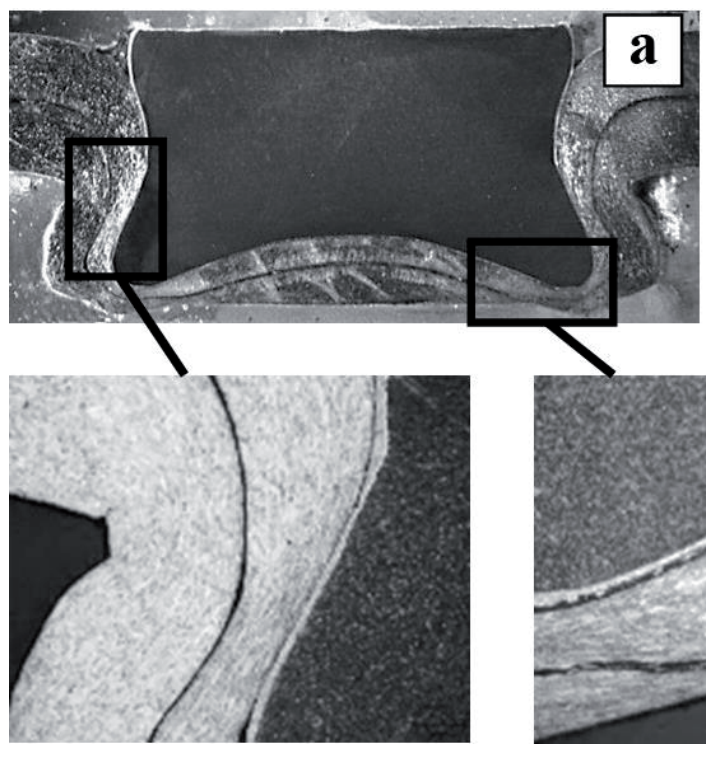

Fig. 9: The critical areas of the joints: a) CR joint and b) CL joint.

Samples with marked areas of microhardness measurements on samples of $C R$ joints and $C L$ joints are shown in Figure 10a. The measured values of samples A with H220PD materials are presented in Figure 10b, samples B with DC6 materials are in Figure 10c, and finally samples C with DX51D materials are shown in Figure 10d. The measurements show the changes in the clinched joint and clinch-riveted joint. The highest microhardness values were measured in the areas of the most significant deformation and material hardening - critical areas. When comparing the microhardness values of $C R$ joints and $C L$ joints, higher values of microhardness were measured on all observed samples joint neck, causing crack formation.

Metallographical analysis confirmed suitability of clinching and clinch-riveting methods for joining the observed material combinations. Both types of failures occurred in the critical area of $\mathrm{CJ}$ joints and CR joints. Figure 9 shows the critical area of both types of joints - the place of the most significant thinning of the joined materials in the area of neck joints. When using CR joints, this area is strengthened with rivets. However, significant thinning or failures were observed in these joints on their bottom parts, e.g. in the place of the transition from the bottom of the joint into the bulge on the bottom's edges.
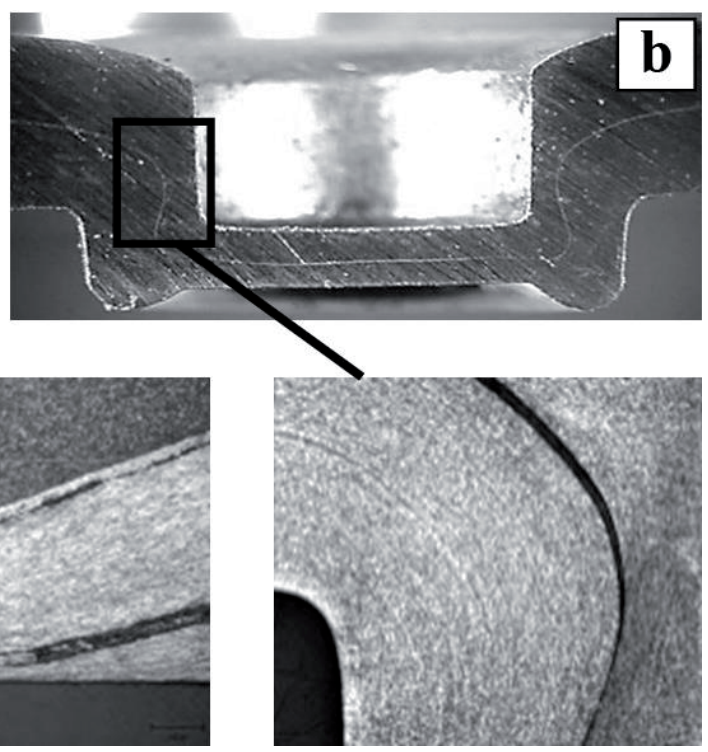

of CR joints, especially in the places marked as 4 and 9 . In these places, the rivet caused greater deformation and material hardening of the joined materials in comparison with the $\mathrm{CL}$ joints.

\section{Conclusion}

The connection of sheet metals is one of the problems of lightweight material needed to confront and solve. New joining solutions, including the plastic forming processes are more extensively used in the sheet metal structure assembly processes.

Clinching as well as clinch-riveting processes have become more and more popular during the last decades. The methods of clinching and clinchriveting are suitable for joining the tested materials. 


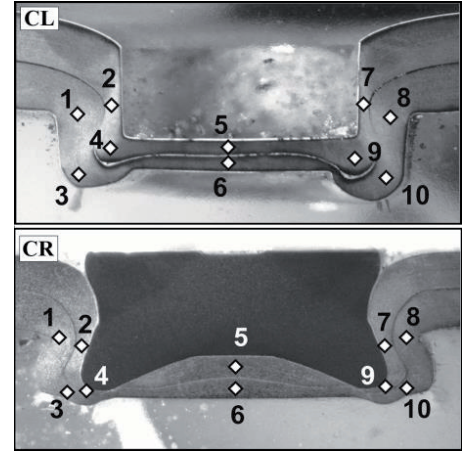

a)

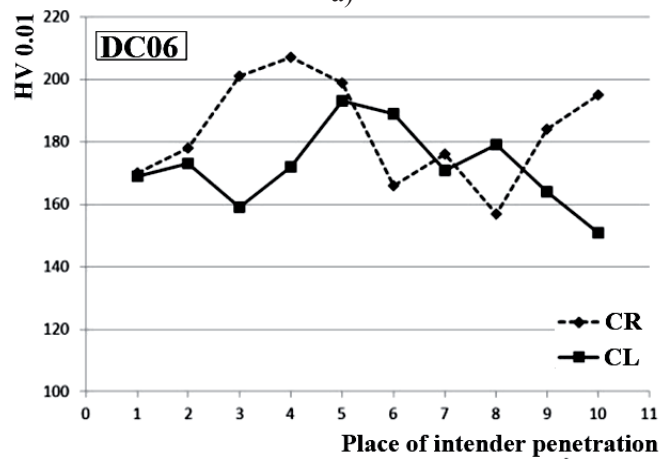

c)

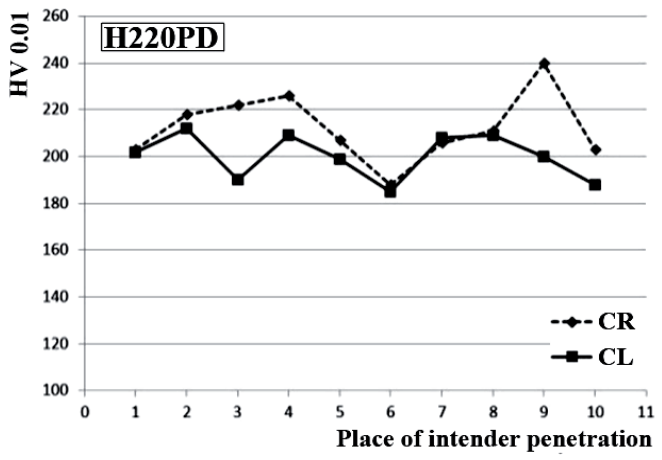

b)

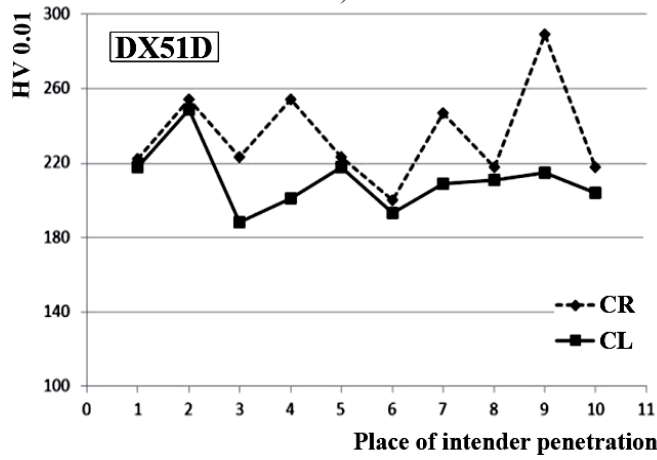

d)

Fig. 10: Microhardness values of $C L$ and $C R$ joints: a) measured locations of microhardness, b) sample A with H22OPD, C) sample B with DC06 and d) sample ( with DX51D.

All tested samples of clinch-riveted joints reached higher values of carrying capacities in comparison with clinched joints. The maximum load values of clinched joints and clinch-riveted joints were 1020 $\mathrm{N}$ and $4790 \mathrm{~N}$ for the samples of H220PD materials, $853 \mathrm{~N}$ and $3857 \mathrm{~N}$ for the samples of DC06 materials, and $1467 \mathrm{~N}$ and $4798 \mathrm{~N}$ for the samples of DX51D materials.

The carrying capacities of these samples were sufficient and the metallographical analysis confirmed no occurrence of cracks or failures in the area of joints during both joining processes.

Using the clinch-riveting method led to significant hardening of the joint in the critical area in comparison to the classical clinching method. This result was evident from the values of carrying capacities of the joints.

The highest values of microhardness were measured in the areas with the most significant thinning of the joined materials as well as in the areas with the most significant hardening of joined materials in both types of joining.
Clinching and clinch-riveting methods offer numerous advantages, however, the most significant limitation is the exterior protrusion, which results in a bump jutting out of the sheet plane. Because of this protrusion, clinching and clinch-riveting technology cannot be used for visible areas (car body shells) or functional surfaces (sliding surfaces).

\section{Acknowledgments}

Authors are grateful for the support of experimental works by project APVV-0682-11: "Application of progressive tool coatings for increasing the effectiveness and productivity of forming sheets made of modern materials".

\section{References}

[1] Kaščák L., Mucha J., Slota J., Spišák E. (2013). Application of modern joining methods in car production. Oficyna Wydawnicza Politechniki Rzeszowskiej, Rzeszów.

[2] Barnes T.A., Pashby I.R. (2000). Joining techniques for aluminium spaceframes used in automobiles: Part II — adhesive bonding and mechanical fasteners. Journal of Material 
Processing Technology, vol. 99, no. 1, pp. 72-79.

[3] Spišák E., Kaščák L.., Viňáš J. (2011). Research into properties of joints of combined materials made by resistance spot welding. Chemické listy, vol. 105, no. 16, pp. 488-490.

[4] Gerstmann T, Awiszus B. (2014). Recent developments in flat-clinching. Computational Materials Science, vol. 81, pp. 39-44.

[5] Mucha J. (2011). The analysis of lock forming mechanism in the clinching joint. Materials and Design, vol. 32, no. 10, pp. 4943-4954.

[6] Sun X., Khaleel M.A. (2005). Performance Optimization of Self-Piercing Rivets through Analytical Rivet Strength Estimation. Journal of Manufacturing Processes, vol. 7, no. 1, pp. 83-93.

[7] Spišák E., Kaščák L’. (2011). Joining car body steel sheets using the clinching method. Acta Mechanica Slovaca, vol. 15, no. 1, pp. 28-34

[8] Zhao S.D., Xu F., Guo J.H., Han X.L. (2014). Experimental and numerical research for the failure behavior of the clinched joint using modified Rousselier model. Journal of Materials Processing Technology, vol. 214, pp. 2134-2145.

[9] Mucha J., Witkowski W. (2014). The clinching joints strength analysis in the aspects of changes in the forming technology and load conditions. Thin-Walled Structures, vol. 82, pp. 55-66.

[10] Mucha J., Kaščák L., Spišák E. (2013). The experimental analysis of forming and strength of Clinch Riveting sheet metal joint made of different materials. Advances in Mechanical Engineering, vol. 2013, pp. 1-11.

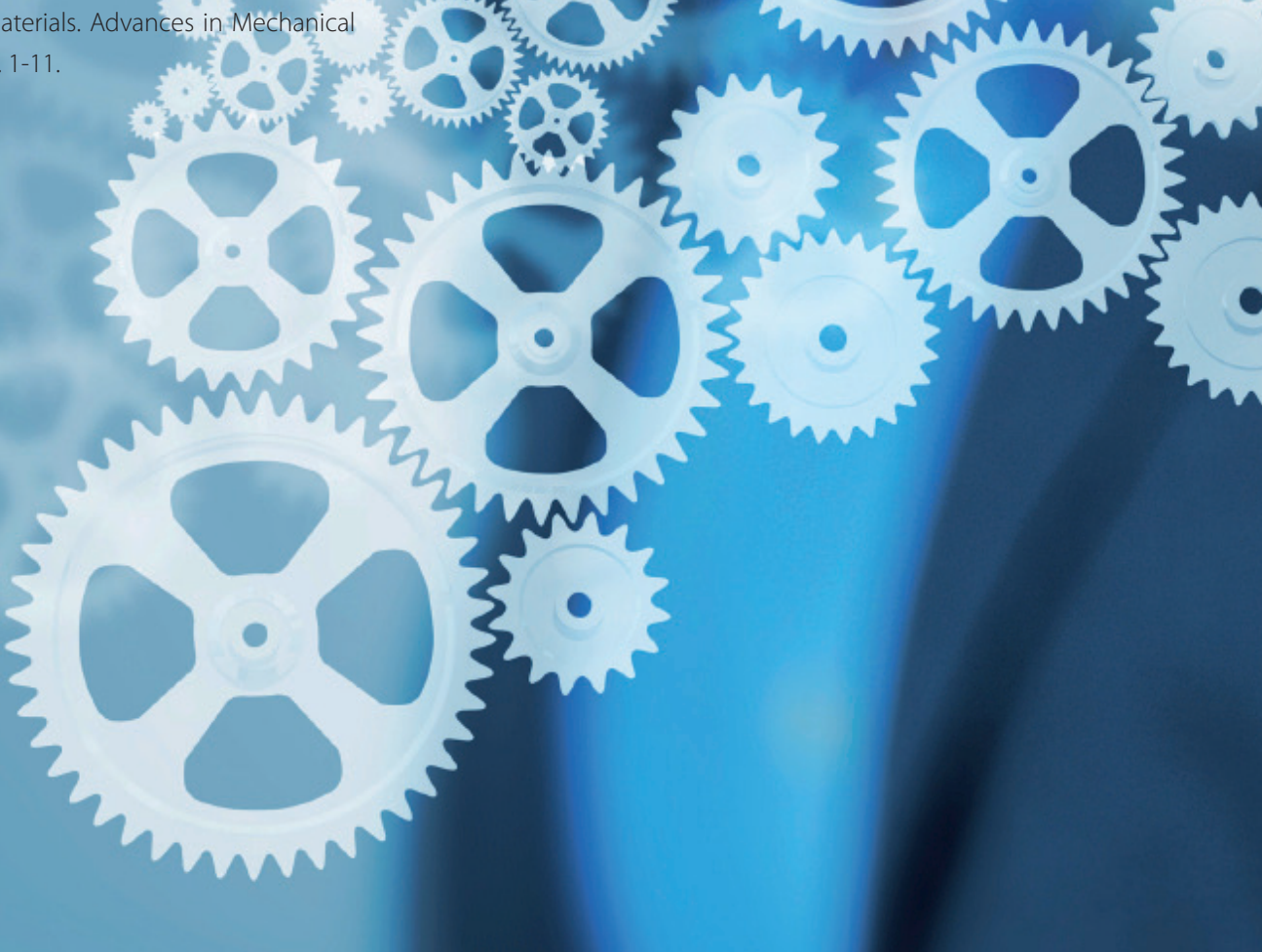




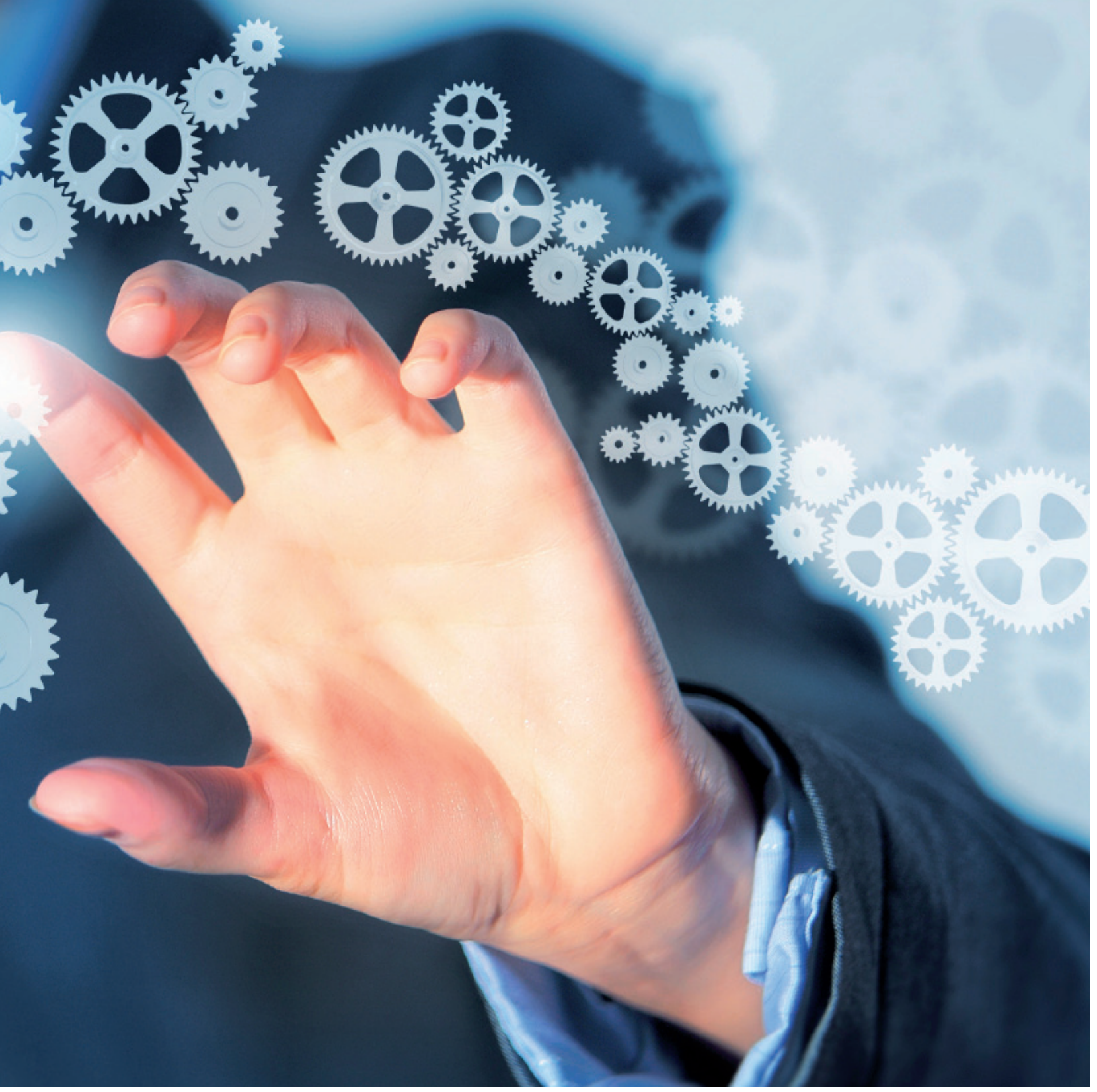

